\title{
Pricing In Portuguese Molds Industry: A Matter Of Survival
}

Ana Isabel Rodrigues, (Email: arodrigues@iscac.pt), Instituto Politécnico de Coimbra, Portugal

Rosa Maria Correia Nunes, Instituto Politécnico de Coimbra, Portugal

\begin{abstract}
This paper intends to present a proposal of pricing model to the Portuguese molds companies, which considers the sector specificities, as the job production system and the used capacity level. After presenting a synthesis of the main theories in literature, we will present a brief characterization of Portuguese molds companies. Finally, we present our suggestion of long term pricing for this sector.
\end{abstract}

\section{Introduction}

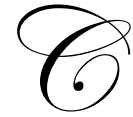

ompetition intensification associated with the globalization of economy and with the high level of customer's demands justify the growing concerning companies and management have about pricing so as to combine their objectives both in competitiveness and profitability. According to Lee (1987), "Traditionally, small service industry companies have had a difficult time developing management control systems that produce reliable pricing information". This statement is also true for Portuguese moulds companies.

This paper aims to contribute to an improvement on the pricing system in the molds sector companies, in a particularly difficult moment for this sector because of the current business cycle. The imperative of improvement in pricing methods is felt, at present, by the generality of Portuguese molds companies, contrarily to what happened in the recent past, owing to the market dependence.

This paper is structured around four points. After the introduction, we will present a synthesis of the main theoretical approaches, reported in the literature on this theme, and then, we will present a brief characterization of Portuguese molds companies, regarding the production process. We will finish this paper by presenting some pricing suggestions for the sector.

\section{Characterization Of Portuguese Molds Sector}

Currently, the molds sector in Portugal is composed of about 300 small and medium sized companies. In spite of being a small economy, Portugal is in eleventh place among the biggest world molds manufacturers and in eighth place concerning molds for the plastic industry. In 2002, according to data published by CEFAMOL - The National Association of the Molds Industry - the export volume represented 88,5\% of the sector production whose main market was France, Germany, Spain, USA and The United Kingdom.

The competitiveness in this sector is the outcome of the continuous technological development, a correct planning of production and the investment in quality control, in human resources qualification, as well as by meeting delivery deadlines and by offering high quality after-sale service, namely technical assistance. The importance of the automobile industry, as a customer of the Portuguese molds is an example of the high sector performance. This industry, which represented $14 \%$ of the sales in 1991 climbed to $50 \%$ in 2002. This increase shows the high performance of this sector at national level, considering the exacting standards of the automobile industry both on quality and on meeting the deadlines. 
Since the beginning of the $90 \mathrm{~s}$, the rate of export/import in the sector has remarkably risen (an average annual growth rate of 15.5\%). However, in 2002, this trend was reversed on account of an increase in imports and a fall in exports. This situation was regarded by the sector manufacturers as a symptom of a probable loss of competitiveness in domestic companies, while these manufacturers are under increasing pressure coming from their customers, to reduce prices and margins.

Concerning the production process and the costing model used by the firm in analysis, based on the information collected throughout several meetings with the CEFAMOL management, we realized that the manufacture may be classified as a complex manufacture of heterogeneous products. Indeed, a relatively large number of phased operations are necessary for transforming the raw material into the finished product. These products, in spite of their diversity, have identical manufacture processes as to the kind of raw material and equipment used. The production is discontinuous and it progresses in several departments. The use of job/orders costing system is the most adjusted to these companies manufacturing characteristics.

\section{Pricing}

"Pricing is an art, not a science" (Needles, 1999) and it "...is an integral part of a marketing strategy to attract consumers..." (Pitts, 1985)

In order to ensure its continuity, a company must have a selling price that is equal or lower than the price charged by its competitors. It also must be accepted by consumers, be able to recover all costs incurred in the course of the product manufacturing (until the finished product is available on the market) and to generate a positive result. Any deviation concerning whichever of these aims will not be acceptable unless it is associated with a precise shortterm objective. Breaking this rule will lead the company to long-term failure.

There are several ways of approaching the pricing subject, and each one of them leads to a different price. The art of pricing depends on the management capacity to interpret the market and anticipate the reaction of consumers to a product and its price. Just knowing the various methods of pricing do not give the manager this capacity.

The molds industry is characterized by a high level of heterogeneity, which gives the sector companies some flexibility in pricing, considering the specificity of their products, as well as the behavior of customers (low demand elasticity-price). Therefore, these firms are confronted with the possibility and necessity of setting a price on their products.

In this industry, the non-existence of a uniform practice of budgeting and pricing is considered by managers as a threat to the profitability and, consequently, to companies survival.

This paper intends to present the main methods of determining the selling price, taking into account the temporal horizon of decisions, all kinds of costs to be considered in these decisions, the degree of utilization of the capacity and the type of customer/order.

We will end this point, by suggesting two pricing methods, the first one concerning the long- term decisions in which the price must cover the total costs incurred in manufacturing and marketing the product (full and absorption costing). As to the short- term decisions, we propose a different pricing method, considering the objective of achieving an acceptable margin on the variable costs.

According to a study to determine conditions under which variable cost pricing was used in a sample of manufacturing firms, published by National Association of Accountants, mentioned by Bruegelman (1985), price controversy between full and variable costs is not clearly defined. There was however frequent use of variable costing for routine pricing in some firms. This study also finds that variable costs were used to meet the competition, when introducing new products, among others, when entering a new product market, on special orders, in bid pricing, on product deletion and for strategic pricing. 


\section{The Market Approach}

According to market approach, pricing must be based mainly on the demand elasticity-price, which indicates the sensitivity of sales to price alterations. Companies may add higher margins to costs if their customers are relatively indifferent to prices (non-elastic demand); otherwise, they should opt for lower margins (elastic demand), in order to secure sales.

By the terms of this approach, pricing must aim the profit maximization, by applying the concept of demand elasticity-price and it shows that the calculation of the optimal selling price must be based on two factors: the sensitivity of sales to price variations and the product variable cost. Indeed, this analysis ignores fixed costs because they are irrelevant to the determination of the optimal price, as these costs do not alter due to the selling price changes.

Considering that molds companies manufacture products with unique characteristics whose market is restricted to a single customer, the utilization of the elastic demand concept does not apply to pricing. However, companies should not ignore this concept so as to be able to anticipate the reactions of their customers to the established price.

\section{The Cost Approach}

The most common practice of pricing consists in adding a margin to the cost, in which case it is necessary to determine both the cost to be considered and the expected margin (Lucas, 2003).

The market approach dealt with the matter of finding the adequate price for customer's expectations and for competitors reaction, while on the cost approach, the initial question is about knowing how much it would cost the company to get the product, in order to set a price that covers this cost and that allows getting a margin.

According to the cost approach, on a long-term horizon, we present two alternative models for pricing, which have distinct processes of calculating the margin to be added to the total cost of the product. In connection with this approach, but concerning the short- term decisions, we also present a pricing method based on the variable cost.

\section{Long-Term Pricing - Absorption Costing}

Pricing based on the absorption costing is grounded on the necessity of covering all costs, in order to guarantee the long-term survival of the company. Firms, following this pricing methodology, begin by calculating the full unit cost in absorption costing, to which they add a predetermined margin. This margin may be calculated on the cost (full or partial cost1) or on the investment2. When employing the full cost, which includes indirect costs, the process of calculating the cost of the product must be very rigorous, as any error in the attribution to indirect costs will provide incorrect information to pricing, or, if the price is determined by the market, it may provide incorrect information about the profitability of the product. In a study on industry practice about what companies are doing with regard to overheads, Cornik (1988) found that "Most major U.S. industries may not be setting appropriate prices for their products."

Generally, companies establish their margins according to the average margin in the sector or to the tradition of the firm.

\footnotetext{
${ }^{1}$ Using the most relevant and weightiest component cost of the total cost.

${ }^{2}$ We do not think it is adequate to use a predetermined rate of return on the investment, in these sector companies, due to the high heterogeneity of the products.
} 
Following this methodology, pricing appears as an apparently simple task, suggesting that it is possible to ignore the demand. Indeed, it seems just necessary to determine the unit cost of the product and establish the intended margin, this way arriving at the price which allows reaching that margin.

However, absorption costing implies that the cost of the product, thus its margin as well, depend on the sales forecast. Consumers may consider the price to be excessive, which will lead to a reduction (matched up to company expectations), in sales and in the unit margin as a consequence of the increase in the unit cost. Therefore, the price may suffer some influence of the company prediction about consumer's and competitor's reactions. In other words, we may say that, in last analysis, the market/customer actually establish the margin and the price.

\section{Short-Term Pricing - Variable Costing}

In practice, it is not always possible to establish a price allowing the company to recover the full cost and get a reasonable margin. One of the reasons for this fact is that management may not have access to what they consider to be an adequate measure of the full cost, especially when this cost includes a high proportion of indirect costs. The other reason is that management can establish prices based on the full cost, only when they use total or almost total installed capacity. According to Kaplan, as referred by Cornick, "...the use of a full cost pricing system can lead to situations were the cost system does not reflect costs of resources in the manufacturing accurately." In situations of overcapacity, at least in the short term, management is faced with decreasing incomes and inevitable fixed costs. In that case, they may be obliged to accept a price which is lower than the full cost, in order to cover at least, part of the fixed costs. If orders exceed the capacity, for a limited period, the company may/must propose a lower price to customers who are willing to accept delivery postponement until a later date, when the capacity is expected to be under-used. So we may say that the possible lowest price is equal to the variable cost. The use of variable cost in pricing decisions is recommended, for export activity in developing nations, by Moustafa (1978) who argues that "...the use of direct-costing methods combined with differential-cost approach will help to establish a floor price which will lead to profit maximization." This price, equal to variable or direct cost, does not lead to a positive result, not even does it contribute to cover the fixed costs. However, this price does not lead to a negative result. Between this minimum cost (variable cost) and the "best" price (full cost plus reasonable profit) there is a range of possible prices. This range is shown in the following figure.

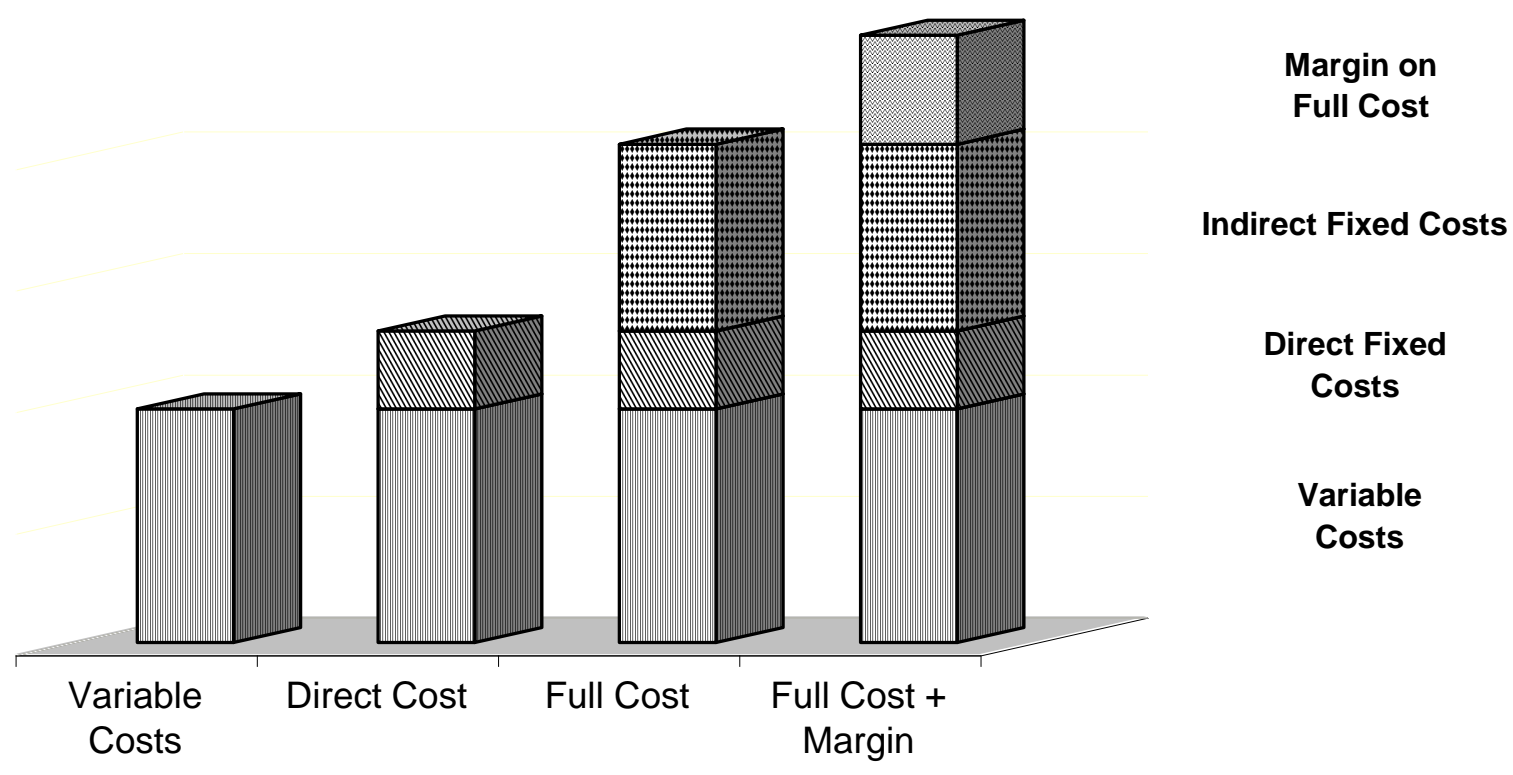


The short term decisions concerning the pricing of extra production orders, which are characterized by using the available productive capacity (not used during that limited period), as well as by not causing any disruption to the regular production, may be taken, based on the variable cost of that production order. In that case, fixed costs are actually irrelevant because they do not alter and are supposed to be covered by the regular production. However, if extra production orders or sporadic contracts (for a limited period) become a significant part of the company regular activity, they turn to be a segment of the activity and they must absorb not only the variable costs but also their share of the company fixed costs.

\section{Synthesis Of Approaches}

In this point, we intend to present a table-summary indicating the different ways of calculating prices, according to the different approaches, the different costing systems, and also the different ways of determining the margin.

\begin{tabular}{|c|c|c|c|}
\hline Approaches & Costing Systems & Margin Calculation & Price Calculation \\
\hline Market & Variable & $\begin{array}{l}\text { Margin calculated on the basis of } \\
\text { price-elasticity of the demand so as to } \\
\text { maximize the result }\end{array}$ & $\mathrm{P}(\max \mathrm{R})=\left(\frac{\varepsilon_{d}}{1+\varepsilon_{d}}\right) \times v c_{u}{ }^{3}$ \\
\hline \multirow{3}{*}{ Cost } & \multirow{2}{*}{ Total (LT) } & Predetermined margin ${ }^{4}$ on the cost ${ }^{5}$ & $\begin{array}{l}\mathrm{P}=\mathrm{VC}+\mathrm{Mg} \\
\mathrm{Mg}=\text { gin RateMar } \mathrm{x} \text { Total Cost }\end{array}$ \\
\hline & & $\begin{array}{l}\text { Predetermined rate return on } \\
\text { investment }\end{array}$ & $\begin{array}{l}\mathrm{P}=\mathrm{VC}+\mathrm{Mg} \\
\mathrm{Mg}=\text { Return rate } \times \text { Investment }\end{array}$ \\
\hline & Variable (ST) & $\begin{array}{l}\text { Contribution margin to covering a } \\
\text { share of the fixed costs }\end{array}$ & $\begin{array}{l}\text { Marginal Price } \\
\mathrm{P}=\mathrm{VC}+\text { Contribution } \mathrm{Mg}\end{array}$ \\
\hline
\end{tabular}

\section{Recommendations}

Considering that the main objective of price decisions is to cover the total costs of the company and get a profit considered acceptable so as to insure the long-term survival of the company, the perfect model would be to determine the price, based on the total cost. However, in some situations, the company should not be held prisoner by this total cost, first for the difficulty in rigorous calculation and ambiguity of this cost, namely in cases of predominant indirect costs (White, 1985), which happens in this sector, secondly for the underused productive capacity, and finally for imperatives of marketing policy. Therefore, we suggest that these companies should calculate, on a regular basis, several types of costs and not just the full and total cost. This pricing methodology was recommended by Lee (1987). This author argues that "The pricing system selected for implementation is a cost-plus approached with a job-order costing process. This system handles overhead costs through the traditional absorption costing approach. A relevant cost approach is used to evaluate special orders, and cost and job information is accumulated on forms. The new system has produced better control over individual jobs, and management is more aware of its control systems." Keeping in mind that, in most of molds sector companies, using the full capacity is not a frequent situation, companies are faced with reduced incomes and inevitable fixed costs. They may therefore have to accept a price that is lower than the full cost, so as to cover a share of the fixed costs. This cost must have the variable cost as a threshold in order to assure a positive contribution margin.

As to the cost approach, we recommend using the normal costs (predetermined cost rate $\mathrm{x}$ actual activity); first because of the absolute necessity to find rapid processes of calculating the product cost and secondly, due to the

\footnotetext{
${ }^{3} \mathrm{P}(\max \mathrm{R})$ is the price which de venda que maximiza o resultado, ${ }^{\mathcal{E}_{d}}$ representa a elastecidade-preço da procura e cvu representa o custo variável unitário.

${ }_{5}^{4}$ According to the company tradition or the sector average.

${ }^{5}$ According to the company tradition or the sector average.
} 
imperative of exclusion of under activity costs (a frequent situation in this sector) and of a large share of the inefficiency costs.

\section{References}

1. McCool, Audrey (1996), "Pricing and cost management for the in-flight foodservice industry", The Bottom Line, October/November, Vol. 11, Issue 7, p. 14-19.

2. Bruegelmann, Thomas M., Haessly, Gaile A., Wolfangel, Claire P., Schiff, Michael, (1985), "How Variable Costing Is Used in Pricing Decisions", Management Accounting, April, Vol. 66, Issue 10.

3. Cornick, Michael, Cooper, William D., Wilson, Susan B. (1988), "How Do Companies Analyze Overhead?", Management Accounting, June, Vol. 69, Issue 12.

4. Diehr, Della M. (1975), "Putting a Price on EDP Services", Journal Of Systems Management, March, Vol. 26, Issue 3.

5. Ellwood, Sheila, (1991), "Costing and Pricing Healthcare", Management Accounting, November, Vol. 69, Issue 10, p. 26.

6. Frishberg, Dov, Uhler, Robert G., (1978), "The Neo-Classical Costing Controversy", Public Utilities Fortnightly, August 3, 1978. Vol. 102, Issue 3

7. Kirill Borissov (1999), "Stability of production prices: A modification to the full-cost approach", "The Manchester School", Jun 1999. Vol. 67, Issue 3, p. 367-391.

8. Konieczny, Jerzy D (1993), "Variable price adjustment costs”, Economic Inquiry, July, Vol. 31, Issue 3, p. 488.

9. Lee, John Y. (1987), "Developing a Pricing System for a Small Business", Management Accounting, March Vol. 68, Issue 9.

10. Lucas M R (2003), "Pricing decisions and the neoclassical theory of the firm", Management Accounting Research, September. Vol. 14, Issue 3, p. 201-217.

11. Moustafa, Mohamed E. (1978), "Pricing Strategy for Export Activity in Developing Nations", Journal Of International Business Studies, Spring/Summer 1978. Vol. 9, Issue 1.

12. Needles and al, (1999), Managerial Accounting, $5^{\text {th }}$ edition, Hougthon Mifflin Company, New York.

13. Pitts, Keith B. (1985), "Pricing and Reimbursement Strategies", Topics In Health Care Financing, Winter Vol. 12, Issue 2.

14. White, Phillip D., Wilsted, William D. (1985), "Value Pricing National Association Of Bank Women", Journal Chicago, Mar/Apr, Vol. 61, Issue 3. 